\title{
Use of Granulocyte Colony-Stimulating Factor Among Patients of Chronic Liver Disease in a Tertiary Hospital in Nepal: A Pilot Study
}

\author{
Rahul Pathak ${ }^{1}$ and Sabin Thapaliya ${ }^{2}$ \\ ${ }^{1}$ Department of Gastroenterology, Institute of Medicine, Tribhuvan University Teaching Hospital, \\ Maharajgunj, Kathmandu, Nepal \\ ${ }^{2}$ Department of Internal Medicine, Institute of Medicine, Tribhuvan University Teaching Hospital, \\ Maharajgunj, Kathmandu, Nepal
}

\begin{abstract}
Introduction: Granulocyte colony stimulating factor improves short-term survival and clinical outcomes in alcoholic hepatitis, acute-on-chronic liver failure and decompensated chronic liver disease. Our study aimed to assess survival benefit and change in Child-Turcotte-Pugh and Model For End-Stage Liver Disease scores 30 days after Granulocyte colony stimulating factor therapy in chronic liver disease patients, irrespective of their mode of presentation.

Methods: This was a prospective observational study conducted in a university teaching hospital, where 25 patients with chronic liver disease were given 300 micrograms of Granulocyte colony stimulating factor subcutaneously 12 hourly plus standard medical therapy. We assessed survival until day 30 . Child-TurcottePugh and Model For End-Stage Liver Disease scores at enrolment and 30 days after treatment were compared. Results: 21 of 25 patients treated with Granulocyte colony stimulating factor survived at day 30 . Treatment with Granulocyte colony stimulating factor reduced Child-Turcotte-Pugh score from $10.33 \pm 1.24$ to $8.76 \pm$ $1.79(\mathrm{p}<0.001)$ at day 30 and Model For End-Stage Liver Disease score from $22.10 \pm 4.67$ to $16.38 \pm 5.52(\mathrm{p}$ $<0.001)$ at day 30 .

Conclusions: Granulocyte colony stimulating factor improves clinical outcome, Child-Turcotte-Pugh and Model For End-Stage Liver Disease scores in patients admitted with chronic liver disease for any cause. Further studies are needed to explore whether lower doses (total six doses) of Granulocyte colony stimulating factor are as effective as higher doses (total 10 doses).

Key words: Chronic Liver Disease; Granulocyte Colony Stimulating Factor
\end{abstract}

Correspondence: Rahul Pathak, Department of Gastroenterology, Institute of Medicine, Tribhuwan University Teaching Hospital, Maharajgunj, Kathmandu, Nepal. Email: Pathak.drrahul@gmail.com

DOI: http://dx.doi.org/10.3126/mjsbh.v18i2.23038

Submitted on: 2019-03-08

Accepted on: 2019-06-08

This work is licensed under creative common license:

http://creativecommons.org/licenses/by-nc-nd/4.0/ C MJSBH 2019 


\section{INTRODUCTION}

Chronic liver injury is defined as hepatic injury, inflammation and/or fibrosis occurring in the liver for more than six months. Chronic Liver Disease (CLD) can be non-cirrhotic or cirrhotic, and cirrhosis can again be classified as compensated and decompensated. ${ }^{1}$ Compensated cirrhosis is defined by the absence of serious symptoms or events like distention of abdomen, haematemesis and jaundice or bouts of altered sensorium. ${ }^{2}$ However, these compensated CLD patients may develop complications with progression of the disease and over time are said to have decompensated. Sometimes, with some known causes of acute decompensation, they deteriorate and end up as Acute on Chronic Liver Failure (ACLF), which has its own definition and criteria given by Asian Pacific Association for the Study of the Liver (APASL) or European Association for the Study of the Liver (EASL) or American Association for the Study of the Liver Disease (AASLD). ${ }^{3}$ Once decompensation has developed, liver transplantation is the only option for survival. CLD has high in hospital mortality. ${ }^{4-5}$ The mortality in certain subgroups is even higher. ${ }^{6}$

Studies have suggested that bone marrow-derived stem cells, stimulated by the glycoprotein Granulocyte Colony Stimulating Factor (G-CSF), might contribute to the regeneration after different kinds of liver injuries. ${ }^{7}$ Recombinant G-CSF has been shown to increase the proliferative capacity of the hepatocytes. ${ }^{8}$ G-CSF has been shown to mobilise $\mathrm{CD} 34+$ cells and increase hepatocyte growth factor, and to induce hepatic progenitor cell proliferation in patients with alcoholic steatohepatitis. $^{9}$

CD34 antigen, present on early hematopoietic and vascular-associated tissue, is an important adhesion molecule with selective role in chemokinedependent cell migration. Mobilisation of CD34+ hematopoietic stem cells has been shown to improve prognosis in other diseases like spinal cord injury and peripheral vascular disease too. ${ }^{10-11}$ G-CSF has shown to improve short-term survival and clinical outcomes in Alcoholic Hepatitis ${ }^{12}$, $\mathrm{ACLF}^{13}$ and Decompensated CLD. ${ }^{14}$

Immune paralysis leads to sepsis and hence Hepato-Renal Syndrome (HRS) and Hepatic Encephalopathy (HE) in patients with cirrhosis. ${ }^{15}$ G-CSF has been shown to improve immune function in patients of liver disease. ${ }^{16}$ In a study GCSF administration was shown to double the percentage of patients with ACLF who survived longer. It also showed significant improvement in CTP (Child-Turcotte-Pugh) scores, MELD (Model For End-Stage Liver Disease) scores, and SOFA (Sequential Organ Failure Assessment) scores and prevented the development of sepsis, HRS, and HE. ${ }^{13}$ Therapy with G-CSF also showed significant reduction in hospital stay. GCSF therapy also improves both the chances of survival and the clinical outcome in patients with decompensated cirrhosis. ${ }^{14}$

Hence, in this pilot study we tried to see if there is any benefit of GCSF in overall chronic liver disease patients, in terms of mortality within one month of hospital admission and improvement in CTP and MELD scores, irrespective of their stage and presentation

\section{METHODS}

This prospective interventional pilot study was carried out at the Department of Gastroenterology, in a tertiary level hospital in Kathmandu, Nepal. First 25 patients meeting the criteria from January 2016 to December 2016 were studied. Written informed consent was taken from each patient or their relatives prior to enrolment in the study. Ethical approval was taken from the Institutional Review Board of the institute.

All patients aged 18 to 75 years admitted with the diagnosis of CLD were included irrespective of the mode of presentation - ACLF, alcoholic hepatitis, decompensated cirrhosis and compensated CLD (irrespective of their etiology). Patients aged $<18$ years and $>75$ years, those with hepatocellular carcinoma or portal vein thrombosis, splenomegaly of $>15 \mathrm{~cm}$, any concurrent evidence of sepsis, Grade 3 or $4 \mathrm{HE}$, pregnancy, hypersensitivity to 
Table 1. Baseline characteristics of the patients

\begin{tabular}{|l|l|}
\hline Variables & Value $(\mathbf{n = 2 5})$ \\
\hline Age $(\mathrm{yrs})$ & $49.4(30-72)$ \\
\hline Sex & $\begin{array}{l}\text { Males }: 18 \\
\text { Females }: 7\end{array}$ \\
\hline Risk factor for CLD & $\begin{array}{l}\text { Alcohol }: 22 \\
\text { Alcohol and viral }: 2\end{array}$ \\
\hline & Others $: 1$ \\
\hline Prior diagnosis of CLD & No $: 20$ \\
\hline Yes $: 5$
\end{tabular}

G-CSF and those who didn't give consent were excluded from the study.

All the patients enrolled, in addition to standard medical treatment as advised by the treating physician, received GCSF injection 300 micro grams subcutaneously twice daily for three days, total six doses. Base line characteristics and lab parameters were recorded. CTP score and MELD scores were calculated at the baseline and at the end of 30 days from the completion of G-CSF therapy.
Table 2. CTP and MELD scores at enrolment and Day $30(n=21)$

\begin{tabular}{|l|r|r|r|r|}
\hline \multicolumn{3}{|c|}{ Mean } & SD & $\begin{array}{l}\text { Co- } \\
\text { rrelation }\end{array}$ \\
\hline Pair 1 & Sig. \\
\hline $\begin{array}{l}\text { CTP score at } \\
\text { enrollment }\end{array}$ & 10.3333 & 1.23828 & 0.467 & 33 \\
\hline $\begin{array}{l}\text { CTP score at } \\
\text { day 30 }\end{array}$ & 8.7619 & 1.78619 & & \\
\hline $\begin{array}{l}\text { Pair 2 } \\
\text { MELD } \\
\text { score at } \\
\text { enrollment }\end{array}$ & 22.0952 & 4.67873 & 0.571 & 0.007 \\
\hline $\begin{array}{l}\text { MELD at } \\
\text { Day 30 }\end{array}$ & 16.3810 & 5.52699 & & \\
\hline
\end{tabular}

Descriptive statistics were expressed as mean (range) or number (\%). Comparison of CTP and MELD scores prior to and after GCSF was done using paired samples t-tests for those patients who survived till the completion of the study. A twotailed $\mathrm{p}<0.05$ was considered statistically significant with $95 \% \mathrm{CI}$. Independent samples t-test was used to analyse baseline quantitative data. Statistical analysis was performed using SPSS v 16.

\section{RESULTS}

164 patients were screened before reaching the first 25 cases that met the inclusion criteria and gave consent. The patients were followed up till one month after enrolment. Their CTP and MELD scores were calculated at enrolment and at the end of one month.

The baseline characteristics of the patients are summarised in table 1. Patients received GCSF at fixed dose of $300 \mu \mathrm{g}$ subcutaneously twice a day for three days. No significant adverse effects requiring dose alteration or stoppage was seen. A few patients developed minor adverse effects like diarrhoea, fever and vomiting after first dose but responded to symptomatic treatment.

Of the 25 patients treated with GCSF, three patients died during treatment in the hospital and one died after discharge but prior to one-month follow up. Of the three patients that died in the hospital in our 


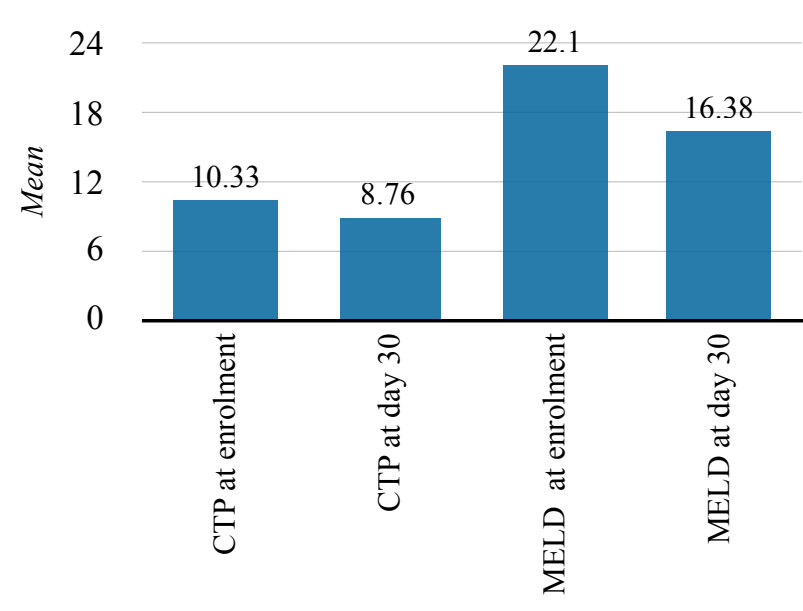

Error Bars: $95 \%$ of CI

Figure 1. Bar diagram showing changes in mean CTP and MELD scores at 30 days

study, one had sepsis, one had HE with AKI and the last one had severe sepsis. Hence, the in-hospital mortality of patients admitted with Chronic liver disease treated with GCSF was $12 \%$ in this pilot study and the one month mortality (irrespective of presentation) was $16 \%$. Treatment with G-CSF showed statistically significant reductions in CTP and MELD scores as shown in Table 2 and 3 and bar diagram (figure 1).

\section{DISCUSSION}

Treatment with GCSF, along with standard treatment, showed significant improvement in clinical outcome as evidenced by improvements in CTP and MELD scores at one month. It also showed good results in terms of decreased inhospital morbidity and decreased mortality rates at one month.
G-CSF has been used in patients with promising results in CLD as well as in animal models of ACLF. ${ }^{17-19}$ Similar promising results were seen in studies in ACLF, alcoholic hepatitis and decompensated CLD. They support our data on the benefits of G-CSF in patients with CLD. First clinical use of G-CSF for possible liver regeneration in advanced liver disease was done by Garg et al. ${ }^{13}$ Duan et al. documented improved three month survival in Hepatitis B-virus associated ACLF patients. ${ }^{20}$ GCSF, with darbopoietin- $\alpha$, has been shown to improve clinical outcomes in decompensated cirrhosis. ${ }^{21}$

G-CSF induces both neutrophil production and release from the bone marrow. ${ }^{22-23}$ Although the exact mechanism of the benefits of G-CSF therapy is not clear, it leads to a significant increase in the CD34 cell population in the liver tissue after four weeks of G-CSF administration. ${ }^{13}$ However, we could not document the increase in CD34 cell in the peripheral blood or the liver tissue. G-CSF may mediate liver regeneration through the use of Hepatocyte Growth Factor (HGF) which is known to promote cell survival and regeneration of tissues. It suppresses chronic inflammation and fibrosis. ${ }^{24}$

Although the mechanisms are not clearly understood yet, G-CSF therapy has shown significant benefit in reducing short-term mortality rates. With the improvement of CTP and MELD scores and reduction in the rates of complications like sepsis, renal impairment or HE, G-CSF has shown therapeutic benefit in all cases of CLD.

Table 3. Paired samples test

\begin{tabular}{|c|c|c|c|c|c|c|c|c|}
\hline & \multicolumn{5}{|c|}{ Paired differences } & \multirow[t]{3}{*}{$\mathrm{t}$} & \multirow[t]{3}{*}{ df } & \multirow[t]{3}{*}{ Sig } \\
\hline & \multirow[t]{2}{*}{ Mean } & \multirow[t]{2}{*}{$\begin{array}{l}\text { Std. } \\
\text { Deviation }\end{array}$} & \multirow[t]{2}{*}{$\begin{array}{l}\text { Std. Error } \\
\text { Mean }\end{array}$} & \multicolumn{2}{|c|}{$\begin{array}{l}95 \% \text { Confidence Interval of the } \\
\text { difference }\end{array}$} & & & \\
\hline & & & & Lower & Upper & & & \\
\hline $\begin{array}{l}\text { CTP score at } \\
\text { enrollment - CTP } \\
\text { at Day } 30\end{array}$ & 1.57143 & 1.63007 & 0.35571 & 0.82943 & 2.31343 & 4.418 & 20 & $<0.001$ \\
\hline $\begin{array}{l}\text { MELD score at } \\
\text { enrollment - } \\
\text { MELD at Day } 30\end{array}$ & 5.71429 & 4.78689 & 1.04458 & 3.53532 & 7.89325 & 5.470 & 20 & $<0.001$ \\
\hline
\end{tabular}


G-CSF is safe for use in these patients with very few minor adverse reactions. In our study, only four out of 25 patients developed complications like fever, vomiting and diarrhoea. However, none of the complications were severe enough to change therapy or stop G-CSF. None of the patients developed the dreaded complication of splenic infarction. Beside daily clinical evaluation, USG abdomen was used to evaluate the increase in spleen size in patients with spleen size $>13.5 \mathrm{~cm}$.

Unlike other studies with $5 \mu \mathrm{g} / \mathrm{kg} /$ dose of G-CSF for a total of 10 doses, we used a total of six doses of $300 \mu \mathrm{g}$ G-CSF subcutaneously. The shorter duration of G-CSF therapy has been tried in patients with hepatitis B virus-associated ACLF in China. ${ }^{20}$ Some significant limitations of our study include the lack of liver biopsy and assessment of
CD34+ cells. A double-blind placebo-controlled trial would have been a better study design.

\section{CONCLUSIONS}

This study showed improvement with GCSF in CLD in terms of CTP and MELD scores and also showed lower in-hospital mortality rates in comparison to mortality rates in older studies without GCSF. Further studies are needed to quantify the survival benefit in these patients, specially compensated CLD alone. Longer follow up studies are needed to see if the benefit is long term. Further studies (head-to-head randomised trials) are needed for comparison of the shorter duration of therapy (total six doses) and longer duration of therapy (total $\geq 10$ doses).

To cite this article: Pathak R, Thapaliya S. Use of Granulocyte colony-stimulating factor among patients of chronic liver disease in a tertiary hospital in Nepal: a pilot study. MJSBH. 2019;18(2):53-9.

Conflict of Interest: None declared

\section{REFERENCES}

1. Walker BR. Davidson's Principles and Practice of Medicine, 22nd ed. Elsevier; 2014. p.932.

2. D'Amico G, Garcia-Tsao G, Pagliaro L. Natural history and prognostic indicators of survival in cirrhosis: A systematic review of 118 studies. J Hepatol. 2006;44(1):217-31.

DOI:10.1016/j.jhep.2005.10.013

3. Jalan R, Gines P, Olson JC, Mookerjee RP, Moreau R, Garcia-Tsao G, et al. Acute-on chronic liver failure. J Hepatol. 2012;57(6):1336-48.

DOI:10.1016/j.jhep.2012.06.026

4. Aldawood A, Alrshed R, Baharoon S, Alsultan M, Aljumah A, Arabi Y. In-hospital mortality among a cohort of cirrhotic patients admitted to a Tertiary Hospital. Saudi J Gastroenterol. 2011;17(6):387.

DOI:10.4103/1319-3767.87179

5. Zubieta-Rodríguez R, Gómez-Correa J, Rodríguez-Amaya R, Ariza-Mejia K, Toloza-Cuta N. Hospital mortality in cirrhotic patients at a tertiary care center. Revista de Gastroenterología de México. 2017;82(3):203-9.

DOI:10.1016/j.rgmxen.2016.10.005

6. Propst A, Propst T, Zangerl G, Öfner D, Judmaier G, Vogel W. Prognosis and life expectancy in chronic liver disease. Dig Dis Sci. 1995;40(8):1805-15.

DOI:10.1007/bf02212706

7. Fogt F, Beyser KH, Poremba C, Zimmerman RL, Khettry U, Ruschoff J. Recipient-derived hepatocytes in liver transplants: A rare event in sex-mismatched transplants. Hepatology. 2002;36(1):173-6.

DOI:10.1053/jhep.2002.33994.

8. Theocharis SE, Papadimitriou LJ, Retsou ZP, Margeli AP, Ninos SS, Papadimitriou JD. Granulocyte-colony stimulating factor administration ameliorates liver regeneration in animal model of fulminant hepatic failure and encephalopathy. Dig Dis Sci. 2003;48:1797-803.

DOI: $10.1023 / \mathrm{A}: 1025463532521$ 
9. Spahr L, Lambert JF, Rubbia-Brandt L, Chalandon Y, Frossard JL, Giostra E, et al. Granulocyte-colony stimulating factor induces proliferation of hepatic progenitors in alcoholic steatohepatitis: A randomized trial. Hepatology. 2008;48(1):221-9. DOI:10.1002/hep. 22317

10. Ning G, Tang L, Wu Q, Li Y, Li Y, Zhang C, et al. Human umbilical cord blood stem cells for spinal cord injury: early transplantation results in better local angiogenesis. Regen Med. 2013;8(3):271-81.

DOI:10.2217/rme.13.26

11. Fujita Y, Kawamoto A. Cell-Based Therapies for Peripheral Arterial Disease. J Stem Cell Res Ther. 2014;4:234. DOI: $10.4172 / 2157-7633.1000234$

12. Singh V, Sharma AK, Narasimhan RL, Bhalla A, Sharma N, Sharma R. Granulocyte colony-stimulating factor in severe alcoholic hepatitis: a randomized pilot study. Am J Gastroenterol. 2014;109(9):1417-23. DOI: 10.1038/ajg.2014.154. Epub 2014 Jun 17.

13. Garg V, Garg H, Khan A, Trehanpati N, Kumar A, Sharma BC, et al. Granulocyte colony stimulating factor mobilises CD34+ cells and improves survival of patients with acute-on-chronic liver failure. Gastroenterology. 2012;142(3):505-12.

DOI:10.1053/j.gastro.2011.11.027

14. Prajapati R, Arora A, Sharma P, Bansal N, Singla V, Kumar A. Granulocyte colony-stimulating factor improves survival of patients with decompensated cirrhosis. Eur J Gastroenterol Hepatol. 2017;29(4):448-55.

DOI:10.1097/meg.0000000000000801

15. Mookerjee RP, Stadlbauer V, Lidder S, Wright GA, Hodges SJ, Davies NA, et al. Neutrophil dysfunction in alcoholic hepatitis superimposed on cirrhosis is reversible and predicts the outcome. Hepatology. 2007;46(3): 831-40.

DOI:10.1002/hep. 21737

16. Visser G1, Rake JP, Labrune P, Leonard JV, Moses S, Ullrich K, et al. Granulocyte colony-stimulating factor in glycogen storage disease type $1 \mathrm{~b}$. Results of the European study on glycogen storage disease type 1. Eur J Pediatr. 2002;161(1):83-7.

DOI:10.1007/bf02680001

17. Gaia S, Smedile A, Omedè P, Olivero A, Sanavio F, Balzola F, et al. Feasibility and safety of G-CSF administration to induce bone marrow-derived cells mobilisation in patients with end stage liver disease. J Hepatol. 2006;45(1): $13-9$.

DOI:10.1016/j.jhep.2006.02.018

18. Lorenzini S, Isidori A, Catani L, Gramenzi A, Talarico S, Bonifazi F, et al. Stem cell mobilisation and collection in patients with liver cirrhosis. Aliment Pharmacol Ther. 2008;27(10):932-39.

DOI:10.1111/j.1365-2036.2008.03670.x

19. Liu F, Pan X, Chen G, Jiang D, Cong X, Fei R, et al. Haematopoietic stem cells mobilised by granulocyte colonystimulating factor partly contribute to liver graft regeneration after partial orthotopic liver transplantation. Liver Transplantation. 2006;12(7):1129-37.

DOI:10.1002/lt.20822

20. Duan XZ, Liu FF, Tong JJ, Yang HZ, Chen J, Liu XY, et al. Granulocyte-colony stimulating factor therapy improves survival in patients with hepatitis $B$ virus-associated acute-on-chronic liver failure. World $J$ Gastroenterol. 2013;19(7):1104.

DOI:10.3748/wjg.v19.17.1104

21. Kedarisetty CK, Anand L, Bhardwaj A, Bhadoria AS, Kumar G, Vyas AK, et al. Combination of Granulocyte Colony-Stimulating Factor and Erythropoietin Improves Outcomes of Patients With Decompensated Cirrhosis. Gastroenterology. 2015;148(7):1362-70. DOI:10.1053/j.gastro.2015.02.054

22. Ulich TR, Del Castillo J, Souza L. Kinetics and mechanisms of recombinant human granulocyte-colony stimulating factor induced neutrophilia. Am J Pathol 1988;133:630-8.

PMID: 2462357

23. Semerad C, Liu F, Gregory A, Stumpf K, Link D. G-CSF Is an Essential Regulator of Neutrophil Trafficking from the Bone Marrow to the Blood. Immunity. 2002;17(4):413-23. 
Original Article Granulocyte Colony -Stimulating Factor in Chronic Liver Disease patients; Pathak R et al. DOI:10.1016/s1074-7613(02)00424-7

24. Nakamura T, Sakai K, Nakamura T, Matsumoto K. Hepatocyte growth factor twenty years on: Much more than a growth factor. J Gastroenterol Hepatol. 2011;26:188-202.

DOI:10.1111/j.1440-1746.2010.06549.x 